\title{
Use of Urology-Based Clinical Practice Guidelines in International Settings
}

\author{
German Patino, ${ }^{*} 1,2$ Medina Ndoye ${ }^{*}{ }^{* 1,3}$ Hannah S. Thomas, ${ }^{* 1,4}$ Andrew J. Cohen, ${ }^{5}$ Nnenaya A. Mmonu, ${ }^{1}$ \\ Carissa E. Chu, ${ }^{1}$ Benjamin N. Breyer, $, 1,6$ \\ *Authors contributed equally \\ 1Department of Urology, University of California San Francisco, United States ${ }^{2}$ Hospital San Ignacio, Bogotá, Colombia ${ }^{3}$ Hôpital Général de Grand Yoff, Dakar, Senegal \\ ${ }^{4}$ University of Edinburgh School of Medicine, Edinburgh, United Kingdom ${ }^{5}$ The Brady Urological Institute at Johns Hopkins, Baltimore, United States \\ ${ }^{6}$ Department of Biostatistics and Epidemiology, University of California San Francisco, United States
}

\section{Abstract}

Objective Clinical practice guidelines (CPGs) serve as frameworks to unify diagnostic criteria and guide clinical decision-making. There is a paucity of literature surrounding the uptake of CPGs in urology practice settings with varied levels of resources worldwide. This study aims to evaluate reported use of CPGs within the context of international urology practice, identify local barriers to uptake, and evaluate the role of stakeholders in the CPGdevelopment process.

Methods This was an international, multi-center, cross-sectional study. An online survey collecting variables pertaining to the use of CPGs was distributed to attending/consultant urologists in Latin America, Africa, and China. Statistical analysis was conducted using R software.

Result A total of 249 practicing urologists from 28 countries completed the survey. The majority of participants were males, aged 36 to 45 , and practiced in a non-academic setting. Ninety-three percent of urologists used CPGs in their everyday clinical practice, and $43 \%$ believed CPGs were very important to medical decision-making. However, barriers such as the lack of adaptability or applicability of CPGs to local settings were mentioned by $29 \%$ and $24 \%$ of participants, respectively. Urologists believed scientific associations (81\%), national urology boards (68\%), and ministries of health (56\%), were important stakeholders to consult to foster the development of local CPGs.

Conclusions Globally, CPGs are widely used tools for clinical practice. However, there are concerns about the adaptability and applicability of CPGs to settings that may lack the resources to implement their recommendations. Efforts should be directed towards incorporating scientific and medical stakeholders into the review and adaptation of urology CPGs to suit the unique features of local health care systems.

\section{Key Words}

$$
\text { Urology, CPG, guidelines, global health, }
$$
barriers

\section{Competing Interests}

$$
\text { None declared. }
$$

\section{Article Information}

Received on: August 4, 2020

Accepted on: October 12, 2020

Soc Int Urol J. 2021;2(1):10-17 


\section{Abbreviations}

AUA American Urological Association

CPG Clinical practice guideline

EAU European Association of Urology

\section{Introduction}

With the large volume of clinical research, it is challenging for practitioners to independently synthesize and review scientific literature to ascertain proper evidence-based care[1]. Clinical practice guidelines (CPGs) are tools used to identify, evaluate, and synthesize recent data and high-quality evidence to assist clinicians in providing evidence-based and outcome-based medicine[2,3]. Developing CPGs mandates multi-professional collaboration through systematic, independent, and transparent methods to produce appropriate quality criteria. When implemented effectively, CPGs have been shown to improve the standardization of medical services, raise the quality of care, promote patient safety, and achieve optimal cost-effectiveness[4]. However, while CPGs are largely considered valuable tools to improve processes of care, associations between adherence to CPGs and patientrelated outcomes remain variable [5-7].

To guide clinical decision-making in urology, CPGs have been developed by major North American and European professional urology organizations such as the American Urological Association (AUA) and European Association of Urology (EAU). In the US, approximately $95 \%$ of urologists reported using the AUA CPGs in regular clinical decision-making[8]. Figures are more variable in European cohorts where Italian urologists' adherence to non-oncologic urology CPGs ranged from $45 \%$ to $88 \%$ [9], while Croatian urologists' compliance with EAU recommendations ranged from $8 \%$ to $100 \%[10]$. More specifically, CPG uptake varies when consulting for pathology and symptom-specific cases such as benign prostatic hyperplasia[11], bladder cancer[12] and asymptomatic hematuria[13]. Younger age and academic practice settings have been found to be associated with greater CPG adherence [8,9].

The uptake of CPGs has not been extensively measured within urology settings of varied resource-levels. It has been hypothesized that CPGs may be valuable tools in low- and middle-income countries (LMICs), where resource constraints limit the development of CPGs suitable to local sociocultural and economic contexts. Cited barriers to CPG implementation in LMICs include inadequate facilities for clinical practice advised by CPGs and comprehensibility of information within CPGs[14]. Multidisciplinary literature has found that CPG implementation in LMICs is often best achieved when coupled with educational programming and adaptation by local experts $[15,16]$.

Through an online survey, this study aimed to evaluate clinical decision-making factors and reported use of urology CPGs produced by professional urology organizations, and national and institutional CPGs. Moreover, we sought to understand the key barriers to individual providers' use of such CPGs. Finally, in an attempt to improve CPG development and better serve international urology practice, we evaluated the importance of key stakeholders.

\section{Methods}

\section{Study design and participants}

This was an international, multi-center crosssectional study. An online survey eliciting urologist demographics and use of and attitudes towards CPGs was disseminated, using means appropriate to the target region. In Latin America, the survey was disseminated to consultant urologists through the email server of several national societies. Similarly, prospective participants in China were invited to complete the survey through the Chinese Urological Association. In Africa, however, participants were more likely to respond if the survey was disseminated through local clinicians and contacts known to a member of the study team. All participants were invited to complete the study through a formalized letter from the research team from the University of California, San Francisco, which included the survey link. In cases of non-response, a follow-up link was provided one month later. Eligible participants were identified as consultant urologists practicing in an international setting. Trainees and residents were not recruited.

\section{Study variables}

A 17-question survey with consent was built through Research Electronic Data Capture (REDCap) and offered in English, Spanish, French, and Chinese (Suppl.) [17]. Demographic variables such as provider age, sex, and years of practice were collected. Knowledge about daily clinical decision-making, knowledge of CPGs, and access to relevant sources of scientific information was sought. The 5-point Likert scale was used to elicit provider perspectives on the role of CPGs in clinical decision-making. Finally, barriers to CPG uptake were investigated, along with provider perspectives on key stakeholders necessary for future CPG development.

\section{Statistical analysis}

Descriptive analyses were conducted using Excel Pivot tables. Through R Studio, chi-square tests of independence were used to approximate statistical significance. 


\section{Ethics}

This study was formally approved through the Institutional Review Board (IRB) within University of California San Francisco (\#18-25978). The study was classed as minimal risk and received exempt IRB status.

\section{Results}

\section{Demographics}

A total of 249 participants, representing 28 different countries, completed the survey (Table 1). Twenty countries were in Africa, 7 in Latin America and 1 in Asia (China). The majority of participants who reported demographic characteristics were men $(92.8 \%$, 192/207) aged 36 to 45 years old (38.6\%, 95/246). Most participants trained in their home country $(70.1 \%$, $143 / 204)$, and reported they were now practicing in a non-academic setting (community, national hospital, or private practice) $(64.9 \%, 135 / 208)$. Seventy-three urologists considered themselves to be working in an academic environment (35.1\%, 73/208). A total of $34.6 \%$ had practiced for 1 to 5 years $(72 / 208)$, and $32.2 \%$ for 16 or more years (67/208). Overall, $33.7 \%$ of sampled urologists were practicing in Latin America (84/249), $31.3 \%$ in Africa (78/249), and 18.5\% (46/249) in China.

\section{Baseline factors contributing to clinical decision-making and access to CPGs}

A total of 43\% (107/249) of responding urologists rated CPGs to be very important during their decisionmaking process, while $25.3 \%(63 / 249)$ greatly valued the role of scientific publications. Similarly, experience and habits, expert opinion, and medical training were

TABLE 1.

Demographics of study participants

\begin{tabular}{|c|c|c|c|c|c|}
\hline Participants & $\begin{array}{c}\text { Africa } \\
\text { n (\%) }\end{array}$ & $\begin{array}{c}\text { Latin America } \\
\text { n (\%) }\end{array}$ & $\begin{array}{l}\text { China } \\
\text { n (\%) }\end{array}$ & $\begin{array}{c}\text { Totals } \\
\text { n (\%) }\end{array}$ & P-Value \\
\hline $\begin{array}{c}\text { Age } \\
25-35 \\
36-45 \\
46-55 \\
56-65 \\
\geq 66\end{array}$ & $\begin{array}{c}28(26.4) \\
51(48.1) \\
15(14.2) \\
9(8.5) \\
3(2.83)\end{array}$ & $\begin{array}{c}30(31.6) \\
29(30.5) \\
15(15.8) \\
15(15.8) \\
6(6.3\end{array}$ & $\begin{array}{c}12(26) \\
15(33) \\
16(35) \\
2(4) \\
0(0)\end{array}$ & $\begin{array}{c}70(28.5) \\
95(38.6) \\
46(18.7) \\
26(10.6) \\
9(3.7)\end{array}$ & 0.0058 \\
\hline $\begin{array}{l}\text { Gender } \\
\text { Male } \\
\text { Female }\end{array}$ & $\begin{array}{l}72 \text { (86.7) } \\
11(13.3)\end{array}$ & $\begin{array}{l}72 \text { (86.7) } \\
11(13.3)\end{array}$ & $\begin{array}{c}44(97) \\
1(3)\end{array}$ & $\begin{array}{c}192(92.8) \\
15(7.2)\end{array}$ & 0.023 \\
\hline $\begin{array}{c}\text { Place of training } \\
\text { Home country } \\
\text { Other countries }\end{array}$ & $\begin{array}{l}36(45.6) \\
43(54.4)\end{array}$ & $\begin{array}{l}62(77.5) \\
18(22.5)\end{array}$ & $\begin{array}{c}45(100) \\
0(0)\end{array}$ & $\begin{array}{l}143(70.1) \\
61(29.9)\end{array}$ & $<0.001$ \\
\hline $\begin{array}{c}\text { Years of practice } \\
1-5 \\
6-10 \\
11-15 \\
\geq 16\end{array}$ & $\begin{array}{l}38(48.1) \\
17(21.5) \\
11(13.9) \\
13(16.5)\end{array}$ & $\begin{array}{c}25(29.8) \\
19(22.6) \\
8(9.5) \\
32(38)\end{array}$ & $\begin{array}{c}9(20) \\
3(6) \\
11(24) \\
22(48)\end{array}$ & $\begin{array}{l}72(34.6) \\
39(18.8) \\
30(14.4) \\
67(32.2)\end{array}$ & $<0.001$ \\
\hline $\begin{array}{l}\text { Type of practice } \\
\text { Academic } \\
\text { Community hospital } \\
\text { National hospital } \\
\text { Private practice }\end{array}$ & $\begin{array}{c}53(67.1) \\
2(2.5) \\
16(20.3) \\
8(10.1)\end{array}$ & $\begin{array}{c}8(9.5) \\
24(28.6) \\
26(31) \\
26(31)\end{array}$ & $\begin{array}{c}12(26) \\
0(0) \\
32(71) \\
1(3)\end{array}$ & $\begin{array}{l}73(35.1) \\
26(12.5) \\
74(35.6) \\
35(16.8)\end{array}$ & $<0.001$ \\
\hline
\end{tabular}

Respondents were in the following countries. In Africa: Algeria, Liberia, Nigeria, Zambia, Senegal, Kenya, Mali, Niger, Madagascar, Gabon, Togo, Ivory Coast, Cameroon, Mauritania, Burkina Faso, Guinea, Morocco, Benin, Republic of the Congo, and Democratic Republic of the Congo. In Latin America: Brazil, Bolivia, Uruguay, Paraguay, Colombia, Argentina, Mexico. In Asia: China. 
considered to be very important by $20.5 \%(51 / 249)$, $13.7 \%(34 / 249)$, and $23.7 \%(59 / 249)$ of participants, respectively. In terms of relevant scientific resources, $30.5 \%(76 / 249)$ of participants greatly valued metaanalyses for consultation during medical decisionmaking, while $25.7 \%(64 / 249)$ emphasized randomized control trials. Ten percent (24/249) of participants believed systematic reviews were important to consider, along with case reports $(6 \%, 15 / 249)$, and case series $(5.2 \%, 13 / 249)$.

The majority of participants confirmed they were able to access the internet from their home $(69.5 \%, 173 / 249)$, mobile phone $(73.5 \%, 183 / 249)$, or local hospital (61.4\%, 153/249). Some participants reported difficulty accessing CPGs through institutional $(26.5 \%, 66 / 249)$ or personal memberships (23.7\%, 59/249). Less than half felt CPGs were easily accessible through open access options $(38.2 \%, 95 / 249)$.

\section{Use of urology CPGs in international settings}

Overall, 92.6\% (225/243) of urologists reported using some form of CPGs in their daily clinical practice (Table 2). Of those who used CPGs, the majority were based at either a national hospital $(30.5 \%, 69 / 226)$ or an academic center $(28.8 \%, 65 / 226)$. In Africa, $87.4 \%$ (90/103) of urologists who responded used CPGs in daily practice, along with $96.8 \%$ (92/95) in Latin America and $95.6 \%(43 / 45)$ in China. The most commonly used CPGs were those from the EAU, as most clinicians reported using them "always" or "frequently" (63.9\%, 159/249) (Table 3). Both CPGs produced by the AUA and the clinician's national urology association were used mostly "frequently" or "sometimes," capturing $80 \%$ (199/249) and 58\% (144/249) of clinicians, respectively, in these categories. In comparison, respondents indicated that they used the joint consultations released by the Société Internationale d'Urologie and the International Consultation on Urologic Diseases "never" or "sometimes" $(70.7 \%, 176 / 249)$, closely followed by guidelines published by the clinician's local institution $(57 \%, 142 / 249)$. Of participating clinicians, 51\% (127/249), reported sometimes consulting "Other" CPG sources as well.

\section{Reported barriers to CPG use}

Among participants, the principal cited barrier to the use of CPGs in everyday practice was the perceived lack of adaptability of the existing CPGs $(29.2 \%$,

\section{TABLE 2.}

Reported use of CPGs across international settings of practice and participant beliefs regarding individual stakeholders' responsibility in the development of CPGs

\begin{tabular}{|c|c|c|c|c|c|}
\hline Participants & $\begin{array}{c}\text { Africa } \\
\mathbf{n}(\%)\end{array}$ & $\begin{array}{c}\text { Latin America } \\
\mathbf{n}(\%)\end{array}$ & $\begin{array}{c}\text { China } \\
\mathbf{n}(\%)\end{array}$ & $\begin{array}{c}\text { Totals } \\
\mathbf{n}(\%)\end{array}$ & P-Value \\
\hline $\begin{array}{c}\text { Use of CPG } \\
\text { Yes }\end{array}$ & $\begin{array}{c}90(87.4) \\
\text { No }\end{array}$ & $\begin{array}{c}92(96.8) \\
3(12.6)\end{array}$ & $\begin{array}{c}43(95.6) \\
2(4.0)\end{array}$ & $\begin{array}{c}225(92.6) \\
18(7.4)\end{array}$ & 0.0279 \\
\hline
\end{tabular}

Type of stakeholder

\begin{tabular}{|c|c|c|c|c|c|}
\hline $\begin{array}{c}\text { Scientific } \\
\text { association }\end{array}$ & $81(76.4)$ & 85 (89.5) & $34(75)$ & $200(81.3)$ & 0.0331 \\
\hline Ministry of health & 55 (51.9) & $63(66.3)$ & $19(42)$ & $137(55.7)$ & 0.0160 \\
\hline Board of urology & 73 (68.9) & $69(72.6)$ & $26(57)$ & $168(68.3)$ & 0.2081 \\
\hline $\begin{array}{c}\text { Non-profit } \\
\text { organization, } \mathbf{n}(\%)\end{array}$ & $15(14.2)$ & $11(11.6)$ & $5(10)$ & 31 (12.6) & 0.8138 \\
\hline $\begin{array}{c}\text { Pharmaceutical } \\
\text { industry }\end{array}$ & $20(18.9)$ & $5(5.3)$ & $2(4)$ & $27(11)$ & 0.0026 \\
\hline Health care provider & 44 (41.5) & $31(32.6)$ & $5(10)$ & $80(32.5)$ & 0.0013 \\
\hline Insurance company & $8(7.5)$ & $9(9.5)$ & $1(2)$ & $18(7.3)$ & 0.3039 \\
\hline
\end{tabular}

Proportions equate to the number of participants who indicated "Yes" to the importance of this stakeholder in the CPG-development process. 


\section{FIGURE 1.}

Reported barriers to uptake of clinical practice guidelines

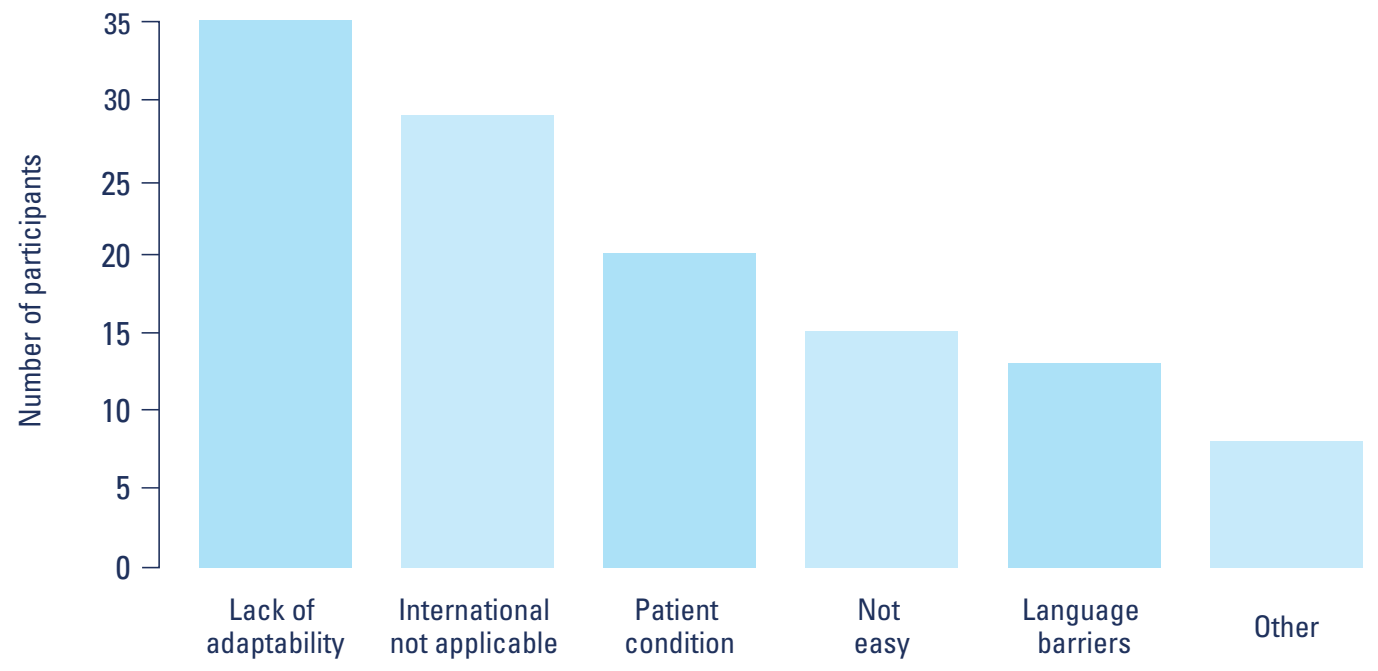

35/120) (Figure 1). Secondarily, participants felt that international CPGs were not applicable to their country $(24.2 \%, 29 / 120)$ or relevant for the health and/or financial status of their patients $(16.7 \%, 20 / 120)$. Open responses from a few participants reported barriers such as cost, time, expertise, and equipment limitations.

\section{Stakeholder responsibility for the development of urology CPGs}

Overall, scientific associations, national urology boards, and ministries of health were believed to be important stakeholders for local CPG development, by $81.3 \%$ (200/246), 68.3\% (168/246), and 55.7\% (137/246) of participants, respectively (Table 2). Seen as less important to the CPG-development process were insurance companies $(7.3 \%, 18 / 246)$ and members of the pharmaceutical industry $(11 \%, 27 / 246)$.

\section{Discussion}

This study affirmed that CPGs for urology are widely used in many countries. Urologists who reported uptake of CPGs are primarily based in national hospitals or academic centers, and consult the EAU, AUA, and the CPGs of their own national urology associations. Ongoing barriers to CPG use in international urology practices relate to the lack of adaptability and relevant, everyday application. In creating CPGs that better serve urologists in resource-variable countries, participants believe that scientific associations, ministries of health, and national urology associations should be involved as key stakeholders.

To our knowledge, this study is the first assessment of CPG use among urologists in resource-variable settings. CPGs are effective tools for crafting evidencebased clinical environments, with the avoidance of inappropriate treatment [4]. However, recommendations that are clinically effective may not necessarily reflect the realities of local constraints; therefore, cost-effectiveness must be considered as well[18]. The World Health Organization affirms that CPGs must have explicit aims and ultimately be targeted to the users themselves[19]. Accredited CPGs are a valuable tool for urologists worldwide, although lack of resources often limits their proper implementation and therefore their usefulness. This study surveyed a broad range of urologists operating in health care systems of varied capacities around the world. In Latin America, recent studies have noted increased use of the GRADE criteria for CPG development; however, there is a paucity of guidelines for relevant, regional pathology[20]. Similarly, in China, where traditional remedies represent $40 \%$ of health care provision, complementary medicine principles may be integrated into the framework of medical CPGs $[21,22]$. Finally, at least one study of CPGs across Africa has indicated that standards of evidence are distinctly different, signaling the need for greater regional crosscollaboration to produce high-quality recommendations [23]. These examples suggest that despite the similar reported use of urology CPGs in Latin America, Africa, and China, these results do not necessarily reflect generalizable knowledge within each distinct region.

Ninety-three percent of urologists reported consulted international CPGs during daily clinical decisionmaking; however, they may not derive the full benefits or the same benefits as urologists in high-resource countries, because the CPGs may lack applicability 


\section{TABLE 3.}

Proportion of Reported Frequency of CPG for Each Type of CPG Stakeholders' Responsibility in the Development of CPGs

\begin{tabular}{|c|c|c|c|c|}
\hline \multirow{2}{*}{ International CPG } & \multicolumn{4}{|c|}{ Reported Frequency of CPG Use } \\
\hline & $\begin{array}{l}\text { Never } \\
\text { n }(\%)\end{array}$ & $\begin{array}{c}\text { Sometimes } \\
n(\%)\end{array}$ & $\begin{array}{c}\text { Frequently } \\
\text { n (\%) }\end{array}$ & $\begin{array}{c}\text { Always } \\
\text { n }(\%)\end{array}$ \\
\hline AUA & $8(3.2)$ & $78(31.3)$ & $121(48.6)$ & $15(6.0)$ \\
\hline EAU & $4(1.6)$ & $59(23.7)$ & $115(46.2)$ & $44(17.7)$ \\
\hline SIU-ICUD Consultation & $66(26.5)$ & $110(44.2)$ & $40(16.1)$ & $4(1.6)$ \\
\hline National Urology Association & $44(17.7)$ & $74(29.7)$ & $70(28.1)$ & $30(12.0)$ \\
\hline Local Institution & $62(24.9)$ & $80(32.1)$ & $56(22.5)$ & $19(7.6)$ \\
\hline Other & $52(20.9)$ & $127(51.0)$ & $25(10.0)$ & $8(3.2)$ \\
\hline
\end{tabular}

AUA: American Urological Association, EAU: European Association of Urology, SIU: Société Internationale d'Urologie, ICUD: International Consultation on Urologic Disorders. "Other" refers to other forms of CPGs not captured in the above categories.

and acceptability in different environments. Existing CPGs may remain "Eurocentric," reflecting the ideals, principles, and knowledge of only a segment of urologists globally. Therefore, strengthening CPG development at the national level may be crucial. Conversely, the development of CPGs is costly, time-consuming, and laborious and may not be a national priority amidst resource-constrained health systems. One recommended strategy for CPGs in resource-variable settings has been the direct adaptation of existing, international CPGs. In South Africa, local practitioners were commissioned to revise international CPGs, with a view to applicability to South African clinical practice[24]. Challenged by factors such as funding and human resources, the case analysis spotlighted a gap in research knowledge and critical appraisal among team members[24]. Additional studies suggest that while urologists desire to practice evidence-based urology, they may not feel they have the necessary appraisal skills to conduct a comprehensive scientific analysis[25]. With this in mind, parallel development of research training and capacity-building should be considered when looking to craft local CPGs.

Finally, equitable access to resources is essential to close the loop and deliver CPGs to local practitioners. Though this access is not universal, our study found that providers are generally able to access the internet through various means. In Africa, participants indicated that internet access for telemedicine is generally available in urban areas, but that access is unreliable in rural regions[26]. However, even in the presence of internet, access to academic literature is variable. In our study, less than half of respondents reported the ability to access open access CPGs with ease. Academic financial barriers such as rising subscription costs and evolving publishing restrictions limit global clinicians' access to sound clinical evidence[27]. In the face of these challenges, some hail open access as a potential solution to mitigate inequities[27]. Authors from low-resource countries may not be able to afford the fees for open access publication, so studies that might be particularly relevant to practice in the region may be subscriptiononly and therefore unavailable[28]. Therefore, while promoting and crafting CPGs that are relevant to local contexts is crucial, the academic community at large must consider how best to support dissemination of this knowledge. Core urology organizations such as the EAU and AUA make their guidelines available free of charge, as models of equitable publishing. However, the majority of our respondents who used CPGs worked at large national hospitals or academic facilities, highlighting an additional, important opportunity to engage providers in non-academic settings.

While our study highlights a known gap in the literature, it has limitations. Although we were able to determine that practitioners appear to be aware of CPGs and/or have the desire to use them, our analysis did not capture the scale and nuance of their use. An exploration of provider perspectives through a mixed-method approach might provide a better understanding of the integration of CPGs in urology practices in resourcevariable areas. Moreover, the authors recognize that 
sampled participants may not necessarily represent generalizable, continent-level findings. Urologists' perspectives were largely compiled through a nonprobable, convenience sampling method, particularly among providers in Africa. The global health literature acknowledges this approach as a strategy for collecting

\section{Conclusions}

Among our international cohort of urologists, reported rates of CPG use were high, indicating widespread awareness of their utility. However, the actual relevance and application of North American and European CPGs in everyday clinical practice is less clear, highlighting barriers to large-scale dissemination and subsequent promotion of evidence-based urology practice globally. Therefore, the development of locally relevant CPGs,

\section{References}

1. Sackett DL, Rosenberg WM, Gray JA, Haynes RB, Richardson WS. Evidence based medicine: What it is and what it isn't. BMJ. 1996; 312:71. https://doi.org/10.1136/bmj.312.7023

2. Kredo T, Bernhardsson S, Machingaidze S, Young T, Louw 0, Ochodo $\mathrm{E}$, et al. Guide to clinical practice guidelines: The current state of play. Int J Oual Health Care. 2016; 28(1): 122-128. doi: 10.1093/ intqhc/mzv115.

3. Bhaumik S. Use of evidence for clinical practice guideline development. Trop Parasitol. 2017; 7(2): 65-71. doi: 10.4103/ tp.TP_6_17.

4. Developing a methodology for drawing up guidelines on best medical practices. (Recommendation (2001)13 and explanatory memorandum). Council of Europe. Z Arztl Fortbild Qualitätssich. 2002; 96 Suppl 3: 5-59. Available at: https://www.ncbi.nlm.nih. gov/pubmed/12964585. Accessed November 20, 2020.

5. Bahtsevani C, Udén G, Willman A. Outcomes of evidencebased clinical practice guidelines: A systematic review. Int J Technol Assess Health Care. 2004; 20(4): 427-433. doi: 10.1017/ s026646230400131x.

6. Lugtenberg M, Burgers JS, Westert GP. Effects of evidencebased clinical practice guidelines on quality of care: A systematic review. Qual Saf Health Care. 2009; 18(5): 385-392. doi: 10.1136/ qshc.2008.028043.

7. Grimshaw JM, Russell, IT. Effect of clinical guidelines on medical practice: A systematic review of rigorous evaluations. Lancet. 1993;342(8883):1317-22. doi: 10.1016/0140-6736(93)92244-n.

8. Breyer BN, Fang R, Meeks W, Lightner D, Clemens J0. Use of the American Urological Association clinical practice guidelines: Data from the AUA census. Urol Pract. 2017; 4: 462-467. https://doi. org/10.1016/j.urpr.2016.10.003

9. Cacciamani G, Artibani W, Briganti A, N'Dow J. Adherence to the European Association of Urology Guidelines: A national survey among Italian urologists. Urol Int. 2018; 100(2): 139-145. doi: 10.1159/000486344. data from hard-to-reach populations, such as isolated urologists operating in regions with limited professional contacts[29,30]. Overall, we believe this study is an important step towards capturing the practice habits of urologists in these situations.

either through the creation of new guidelines or the modification of existing ones, should be a priority for stakeholders in health care systems. An effort to promote international cooperation is essential to help build, adapt, and implement CPGs congruent with the epidemiological and socioeconomic context of a country's needs.

10. Tomašković I, Tomi M, Nikles S, Neretljak I, Milicić V. Croatian urologists' clinical practice and compliance with guidelines in the management of non-neurogenic male lower urinary tract symptoms. Acta Clin Croat. 2015; 54(4): 453-457. Available at: https://www. ncbi.nlm.nih.gov/pubmed/27017719. Accessed November 20, 2020.

11. Strope SA, Elliott SP, Saigal CS, Smith A, Wilt TJ, Wei JT, et al. Urologist compliance with AUA best practice guidelines for benign prostatic hyperplasia in medicare population. Urology. 2011; 78(1): 3-9. doi: 10.1016/j.urology.2010.12.087.

12. Van Rhijn BWG, Burger M. Bladder cancer: Low adherence to guidelines in non-muscle-invasive disease. Nat Rev Urol. 2016; 13(10): 570-571. doi: 10.1038/nrurol.2016.165.

13. Shinagare AB, Silverman SG, Gershanik EF, Chang SL, Khorasani R. Evaluating hematuria: Impact of guideline adherence on urologic cancer diagnosis. Am J Med. 2014; 127(7): 625-632. http://dx.doi. org/10.1016/j.amjmed.2014.02.013.

14. Ismaila N, Salako 0, Mutiu J, Adebayo 0. Oncology guidelines usage in a low- and middle-income country. J Glob Oncol. 2018; 4: 1-6. doi: 10.1200/JG0.17.00136.

15. Docherty M, Shaw K, Goulding L, Parke H, Eassom E, Ali F, et al. Evidence-based guideline implementation in low and middle income countries: Lessons for mental health care. Int J Ment Health Syst. 2017; 11: 1-16. doi: 10.1186/s13033-016-0115-1.

16. Olayemi E, Asare EV, Benneh-Akwasi Kuma AA. Guidelines in lowermiddle income countries. Br J Haematol. 2017; 177(6): 846-854. doi: $10.1111 /$ bjh.14583.

17. Harris PA, Taylor R, Thielke R, Payne J, Gonzalez N, Conde JG. Research Electronic Data Capture (REDCap) - a metadata driven methodology and workflow process for providing translational research informatics support. J Biomed Inform. 2009; 42(2): 377-81. doi: 10.1016/j.jbi.2008.08.010. 
18. Woolf S, Schünemann HJ, Eccles MP, Grimshaw JM, Shekelle P. Developing clinical practice guidelines: Types of evidence and outcomes; values and economics, synthesis, grading, and presentation and deriving recommendations. Implement Sci. 2012;7(1):1-12. doi:10.1186/1748-5908-7-61.

19. WHO. Guidelines in health care practice: Report on the WHO meeting, Schloss Velen, Borken, Germany, 26-28 January 1997. 1997;(45). https://apps.who.int/iris/handle/10665/107628.

20. Cabrera PA, Pardo R. Review of evidence based clinical practice guidelines developed in Latin America and Caribbean during the last decade: An analysis of the methods for grading quality of evidence and topic prioritization. Global Health. 2019;15(1):1-10. doi:10.1186/ s12992-019-0455-0.

21. Hesketh T, Zhu WX. Health in China. Traditional Chinese medicine: One country, two systems. BMJ. 1997;315(7100):115-117. doi:10.1136/bmj.315.7100.115.

22. Chen Y, Wang C, Shang H, Yang K, Norris SL. Clinical practice guidelines in China. BMJ. 2018;360. doi:10.1136/bmj.j5158.

23. Okwen PM, Maweu I, Grimmer K, Margarita Dizon J. Evaluation of all African clinical practice guidelines for hypertension: Quality and opportunities for improvement. J Eval Clin Pract. 2019;25(4):565574. doi:10.1111/jep.12954.

24. McCaul M, Ernstzen D, Temmingh H, Draper B, Galloway M, Kredo T. Clinical practice guideline adaptation methods in resourceconstrained settings: Four case studies from South Africa. BMJ Evid Based Med. 2020; 25(6):193-198. Epub ahead of print 10 July 2019: 1-6. Available at: https://www.ncbi.nlm.nih.gov/pubmed/31292208. Accessed November 20, 2020.
25. Dahm P, Poolman RW, Bhandari M, Fesperman SF, Baum J, Kosiak $B$, et al: Perceptions and competence in evidence-based medicine: A survey of the American Urological Association membership. J Urol. 2009; 181(2):767-77. doi: 10.1016/j.juro.2008.10.031. Epub 2008 Dec 16.

26. Fraser HSF, McGrath SJD. Information technology and telemedicine in sub-Saharan Africa. BMJ. 2000;321(7259):465-466. doi:10.1136/ bmj.321.7259.465.

27. Chan L, Arunachalam S, Kirsop B. Open access: A giant leap towards bridging health inequities. Bull World Health Organ. 2009;87(8):631635. doi:10.2471/BLT.09.064659.

28. Smith E, Haustein S, Mongeon P, Shu F, Ridde V, Larivière V. Knowledge sharing in global health research - the impact, uptake and cost of open access to scholarly literature. Health Res Policy Syst. 2017;15(1):1-10. doi:10.1186/s12961-017-0235-3.

29. Shaghaghi A, Bhopal RS, Sheikh A. Approaches to recruiting "hardto-reach" populations into re-search: A review of the literature. Health Promot Perspect. 2011;1(2):86-94. doi:10.5681/hpp.2011.009.

30. Valerio MA, Rodriguez N, Winkler P, Lopez J, Dennison M, Liang Y, et al. Comparing two sampling methods to engage hard-to-reach communities in research priority setting. BMC Med Res Methodol. 2016;16(1):1-11. doi:10.1186/s12874-016-0242-z. 